Shepherd, R., \& Wilkinson, M. (2020). Operating in the dark: The identification of forced labour in the UK. Critical Social Policy. (Copyright Holder). Copyright (C 2020 by Critical Social Policy Ltd. https://doi.org/10.1177/0261018320921540.

\title{
Title
}

\section{Operating in the Dark: The identification of Forced Labour in the UK}

Rowena Shepherd, Mick Wilkinson

\begin{abstract}
Presented here are the findings of a research study undertaken between 2015 and 2018 that focused on existing arrangements and mechanisms for front-line identification of the victims of forced labour in the UK. The study drew upon interviews with service professionals in enforcement and policing organisations together with workers in non-governmental victim support agencies. These findings reveal significant failings in current approaches, that suggest processes for the identification of victims remain, at best, uneven from service to service, location to location, at worst wholly inadequate. The study also exposed widespread stakeholder concerns around UK government regulatory guidance and immigration policies, suggesting that these were hindering rather than assisting them in the process of identification. Further, that the deregulated employment environment was one in which forced labour practices could both thrive and remain well-hidden amongst wider employer exploitation and abuse.
\end{abstract}

\section{Key words}

Forced labour, identification, deregulation, hostile environment 


\section{Introduction}

Over the past two decades, statutory and voluntary agencies, investigative journalists and academics have evidenced forced labour, a form of Modern Slavery in the UK in diverse industries and locations (Skrivankova, 2006; Scott et al., 2012). Official statistics and estimates from a range of sources suggest that the malaise continues and has grown exponentially in recent years (Grierson, 2017; Global Slavery Index, 2019).

In 2005, in the wake of the Morecambe Bay cockle picking tragedy, the Gangmasters Licensing Authority (GLA) was established to regulate those supplying temporary labour. This remains the sole agency statutorily tasked with assessing workplaces for forced labour. The UK Human Trafficking Centre was created in 2006 to combat people trafficking. In 2014, Theresa May, then Home Secretary, introduced the UK's Modern Slavery Strategy, declaring:

'The time has come for concerted, coordinated action. Working with a wide-range of partners, we must step up the fight against modern slavery.... we must do all we can to protect, support and help victims, and ensure that they can be returned to freedom' (HM Government, 2014:6).

The 2015 Modern Slavery Act (MSA) was followed by the Immigration Act 2016. The latter expanded the GLA to the Gangmasters and Labour Abuse Authority (GLAA) and created the Director of Labour Market Enforcement intended to coordinate labour enforcement activities (Broadbent, 2017). For all that, forced labour persists, apparently unchecked. For perpetrators the potential gains are enormous, the risk of punishment minimal. For victims, support is at best limited and fragmented.

Presented here are the findings of a research study undertaken between 2015 and 2018 at the University of Hull and the Wilberforce Institute, Hull (Shepherd, 2018). The study focused on forced labour in the UK and investigated whether the existing legislative and administrative arrangements tackling forced labour were fit for purpose. It sought to expose challenges preventing identification of the presence of forced labour and reveal any obstacles hindering victims from obtaining redress. This article focuses on the efficacy of existing arrangements and mechanisms for front-line identification of the victims of forced labour. 


\section{What is Forced Labour?}

Forced labour was defined in the International Labour Organisation's (ILO) Forced Labour Convention (No 29) 1930 as 'all work or service which is exacted from any person under the menace of any penalty and for which the said person has not offered himself voluntarily.' In November 2016 the ILO's Protocol of 2014 to the Forced Labour Convention, 1930, (PO29), entered into force elucidating the definition of forced labour (ILO, 2014). "All work or service" included 'all types of work, service and employment, occurring in any activity, industry or sector, including in the informal economy;' "Menace of any penalty" incorporates 'a wide range of penalties used to compel someone to perform work or service, including penal sanctions and various forms of direct or indirect coercion, such as physical violence, psychological threats or the non-payment of wages. The "penalty" may also consist of loss of rights or privileges (such as promotion, transfer, or access to new employment).'

\section{The scale and form of Forced Labour in the UK}

Forced labour occurs across the UK in a wide range of sectors particularly where temporary workers are employed. Anti-Slavery International's seminal Trafficking for Forced Labour: UK Country Report (2006), uncovered forced labour in 'agriculture, construction, domestic work, food processing and packaging, care/nursing, hospitality and the restaurant trade'. It found trafficked people 'forced to work in motorway services, as casual labour in ports, doing laundry and in nail parlours.' People were compelled into 'illicit activities such as shoplifting, pick-pocketing and the sale of pirate CDs and DVDs on the street' (Skrivankova, 2006:1). Exploitation is associated with 'washing cars, heavy manual labour at ports, collecting shopping carts in parking lots' (Skrivankova, 2006:15). Adults and children are pressured into illegal activities such as street begging, shop lifting, cannabis farms and benefit fraud (Fouladvand, 2015; Gentleman, 2017).

Industries associated with forced labour generally operate in highly competitive markets, where the work is low skilled and wages a large proportion of the costs (Anderson and Rogaly, 2005:24). Also undertakings 'that depend on casual or temporary labour, offer low wages, predominantly subcontract, and where it is often hard to track supply chains' 
(Skrivankova, 2006:15). Victims often work excessive hours, in hazardous conditions, without a legal contract of employment. When paid, wages can often be subject to illegal deductions. Victims are invariably provided with overcrowded, poor standard accommodation (CPS, 2016). In the UK, as elsewhere, the boundaries between severe labour exploitation, forced labour and slavery are blurred. Unpleasant and unsociable labour and conditions contrary to human dignity segues to unsafe working conditions involving coercion and violence. Many UK migrant workers move through and between those boundaries and 'there is no objective and clear line demarking the beginning and the end of one form of exploitation from another' (Skrivankova, 2010: 17).

When this study commenced in 2015, official government sources estimated UK victims of modern slavery and human trafficking at approximately 13,000 (Silverman, 2014). Modern slavery enforcement focused on trafficking for the sex trade. Awareness of forced labour was limited, so many victims were not identified as such (Craig et al., 2007:41). However, academics at the Wilberforce Institute, (Wilkinson et al, 2010:31-35) and stakeholders such as Anti-Slavery International signalled their belief that official victim estimates were considerable underestimates. This has since been recognised by the National Crime Agency (NCA) who today consider those enslaved to number 'tens of thousands' (Grierson, 2017), whilst the Global Slavery Index estimates the figure at 136,000' (Global Slavery Index, 2019).

\section{Vulnerable Workers in the UK}

The Trade Union Congress'(TUC) Commission on Vulnerable Employment report of 2008 estimated that 'around two million workers in the UK find themselves in vulnerable employment', defined as 'precarious work that places people at risk of continuing poverty and injustice resulting from an imbalance of power in the employer-worker relationship'(TUC, 2008:3). Further, it found that: 'Some of the most extreme employment rights abuses involve employment agencies and temporary labour providers' (TUC, 2008:117).

Over the past decade, the vulnerable have undoubtedly increased given the explosion of zero hours contracts and increased extent of labour contracting. For millions of UK workers precariousness in employment is now the norm (Standing, 2011). In the era of 'austerity,' 
benefit cuts and sanctions and an increasingly fractured safety net, it is a reasonable assumption, illustrated by several recent prosecutions, that a considerable number of vulnerable British nationals are also becoming ensnared in slave like working conditions (Beatty et al., 2015: 32-35, Vernalls, 2017). As more is uncovered about 'county lines' (the term for city drug gangs exploiting vulnerable people while expanding into smaller towns) these may prove to be the tip of the iceberg (NCA, 2018).

\section{Asylum and Forced Destitution}

The UK Asylum process is one of the harshest to navigate in Europe. Souter (2011) found there to be a 'culture of denial' amongst asylum case officers. Regardless of the veracity of the case, immigration officers have reported colleagues deliberately denying asylum to legitimate claimants, describing a process so fraught with error and mismanagement that it was a 'lottery' (Taylor, Muir, 2010; Brewer, 2018). There have been hundreds of thousands of asylum rejections (Independent Asylum Commission, 2008: 6). In October 2017, the Home Affairs Committee (2017) heard, 'There are probably over a million foreigners here illegally at the moment. There is a large number, so no-one can ever remove those.' This suggests numbers are growing, the Home Office median estimate in 2001 being 430,000 (IPPR, 2006).

Restrictions on the right to work combined with the Care Act 2014 s.21 explicitly preventing local authorities from supporting people needing care or who are destitute because of their immigration status, condemns countless numbers to destitution and homelessness (Lyons et al., 2017; Kidd et al., 2019). Undocumented migrant workers are obliged to live an 'underground' existence, vulnerable to appalling exploitation, forced labour and worse. Their irregular status and twilight existence renders them outside of the protection of labour-related enforcement agencies. They represent a vast pool of exploitable labour. Some migrants knowingly arrive in the UK illegally. Many arrive in good faith, only to become illegal through being deceived by their traffickers or through gangmasters taking their papers but failing to register them with the authorities (Wilkinson et al, 2010:25). Many undocumented migrants are indebted upon arrival in the UK, having agreed to work off large, non-returnable sign-on fees, or through accruing further unexpected fees. Thenceforth, by means of: 
'systematic irregular deductions from wages, incomplete wages, sporadic employment patterns, tied accommodation, removal of passports, and threats to themselves and their families back home, combined with their often poor language skills and a lack of awareness of their rights, they are effectively enslaved by being unable to leave and unable to clear their 'debt' (Craig et al., 2007:37-38).

Most are too frightened to approach statutory authorities. A situation not helped by many statutory agencies cooperating with immigration officials in workplace sweeps seeking illegal workers (Corporate Watch, 2016). Such raids encourage fears that the government's intention is incarceration and deportation of exploited migrant labour. Studies suggest raids make the undocumented more vulnerable to exploitation, pushing them 'into more exploitative working practices', make them 'less likely to report violations' and 'more resistant to trade union or other organizing efforts' (Bloch et al, 2014).

Most of the temporary labour market is non-unionised and when trade unionists do uncover abuses, their actions may be inhibited precisely because victims are vulnerable to deportation (Wilkinson et al, 2010:73). Further considerations include isolation, not knowing where to turn for assistance or simply too busy scraping by to seek assistance (Lewis et al., 2015:125).

\section{UK Government Response}

The 1930 Convention and subsequent Protocols bind the UK to develop a national policy and plan of action to tackle forced labour. Article 1(2) of the 2014 Protocol (P029) requires inter alia 'systematic action by the competent authorities ... in coordination with employers' and workers' organizations ... with other groups concerned.' The landmark Modern Slavery Act 2015 (MSA) criminalised forced labour and human trafficking, defining both as modern slavery. It introduced an 'Independent Anti- Slavery Commissioner' (IASC) to oversee the government's anti-slavery strategy. Other provisions included the protection of victims, slavery and trafficking prevention orders, with courts empowered to issue reparation orders to compensate victims. Section 52 imposed a 'duty to notify' on public authorities if slavery was suspected. Section 54 required larger businesses to report annually on measures taken to ensure that slavery is not present in their business or supply chains (UK Government, 2015). The MSA has been criticised as too vague and limited in scope, in particular regarding the 
plight of overseas domestic workers vulnerable to exploitation because their visas legally tie them to their employer (ATMG, 2016:72-4; Craig, 2017; Field et al., 2018). This study did not intend to evaluate the overall impact of the MSA anti-slavery measures per se. However, their efficacy depends in turn on the administrative National Referral Mechanism (NRM) and the ability of First Responders to identify victims.

The NRM is a specialist capability within the National Crime Agency 'for identifying victims of human trafficking or modern slavery and ensuring they receive the appropriate support' (NCA, 2016a: NRM). An administrative arrangement of this kind is mandated by the MSA. Potential victims can only be referred into the system, subject to their signed consent, by an authorised agency or first responder. First responders are specified to be police forces, the UK Border Force, the GLAA, local authorities and a number of charities such as the Salvation Army, Migrant Help, Kalayaan and Barnardos (NCA, 2016a: NRM).

The reason for restricting reporting to these groups is not obvious. After all, potential victims might be discovered by anyone anywhere. It has been suggested that HM Prison Service also be included (CSJ, 2013:72). Trade unions are also omitted. Given their understanding of exploitative practices, and connection to workers who may work alongside those in forced labour, it is difficult to view this as anything other than an ideological decision. Competent Authorities (CA) in the NRM assess individual cases. Within 5 days of referral, they 'decide whether there are reasonable grounds to believe an individual is a potential victim of human trafficking or modern slavery' (NCA, 2016a). Probable victims of exploitation are offered 45 days so-called 'recovery and reflection' in a safe environment while the CA gathers further evidence. A 'Conclusive Decision... on the balance of probability' determines whether an individual is a victim who is subsequently supported (NCA, 2016a:NRM).

\section{Identifying Forced Labour situations}

There is nothing systematic about the UK government's arrangements for identifying forced labour. Beyond the activities of the GLAA and a few specialist police units, it relies primarily on victims self-reporting, observations from the general public or on other agencies encountering it in the course of their work. In his 2016 Annual Report the Independent Anti 
Slavery Commissioner (IASC) claimed existing NRM referrals were 'the tip of the iceberg', continuing: 'I want to see more victims being identified, referred for appropriate support and restored of their freedom. At the moment there are too many gaps in the system for victims to fall through' (2016:2). The IASC Strategic Plan 2015-17 committed to 'drive improved identification of victims of modern slavery', ensuring 'appropriate training and checks are in place for border and immigration officials to be better equipped to identify potential victims and suspected traffickers (1.12); Collaboration with public authorities and health agencies across the UK to ensure that appropriate victim identification training is in place'(1.13) and the promotion of 'awareness raising and training for local authorities, the health sector and relevant statutory agencies' (1.14) (IASC, 2015).

In February 2017, the IASC reported 'Identification of both victims and criminals needs major improvement' noting training provision was insufficient 'to equip Border Force frontline officers with the necessary tools to identify and support victims at the border' (ICIBI, 2017: 2). He posited the "strong chance we are missing thousands of victims of modern slavery at our borders" (Travis, 2017). Further, reports from the frontline suggest that a range of service providers, from the police (HMICFRS, 2017) to NHS professionals (Protect, 2015:12-13) continue to struggle with the very concept of modern slavery, what forms it takes and how to identify it.

Official suspicion of the veracity of potential victims has been well documented. Border officials consider evidence as fake and 'view the person as an illegal migrant first ... allegations are made as an attempt to stay in the UK' (ATMG, 2013:43). Historically, the police also failed in their responsibilities, victims being either 'misidentified as civil claimants by police reception staff or refused assistance altogether.' For some their visit 'resulted in detention whilst attempting to report trafficking' (ATMG, 2013:43). Institutional racism in the police and wider public service may also influence decisions (Macpherson, 1999:27-46).

Although there is some understanding of how individuals are trafficked into the UK and then exploited in forced labour, research suggests: 
'little understanding of forced labour that occurs without trafficking, and almost no recognition that refugees and asylum seekers are susceptible to forced labour' (Lewis et al., 2015:173).

Forced labour is difficult to recognise. To the casual observer, forced labour situations may appear unremarkable. Even seasoned labour enforcement officials are not always confident when they come across forced labour. It is challenging differentiating between a scenario legally qualifying as forced labour, from one of simple exploitation. For example, 'gig economy' jobs and agency-based employment, characterised by precarious employment, zero and tiny hours contracts, whilst legal, may nonetheless involve conditions considered as exploitative and/or abusive.

Vague legal definitions do not help. The consensus is that 'Indicators' greatly assist identification. Although a single indicator suggests the presence of forced labour, it is generally accepted that finding two or more indicators together provides a more solid basis for identifying a forced labour situation (Craig et al., 2007:18). In 2012, the ILO listed 11 indicators of force labour: 'Abuse of vulnerability; Deception; Restriction of movement; Isolation; Physical and sexual violence; Intimidation and threats; Retention of identity documents; Withholding of wages; Debt bondage; Abusive working and living conditions; Excessive overtime' (ILO, 2012).

\section{Research Aims and Methodology}

The study aimed to provide a current picture of the scale and extent of forced labour in the UK. It sought to identify any difficulties in uncovering and confirming its presence and any barriers preventing victims from seeking assistance from the authorities. It was premised that by questioning individuals who interact with workplaces and deal with the crime, their

opinions and experiences might indicate shortcomings in government arrangements.

Participants were chosen on the basis of their proximity to employment environments that previous research suggested might harbour forced labour in some form or another. Those who had experience of operating across a range of work places were preferred. Relevant officials included those with a statutory obligation to inspect workplaces or examine work circumstances such as fire officers who visit to assess fire precautions, environmental health officers and food hygiene inspectors as well as national agencies such as HSE and the GLAA. 
Trade unions, the police and immigration services, and voluntary agencies, such as the Salvation Army and Citizens Advice Bureau, all seemed potential sources of relevant experience about forced labour. In total, interviews were conducted with 18 participants: 3 trade unions officials, 4 voluntary sector workers, 5 environmental health officers, 3 HSE inspectors, 2 fire brigade inspectors, 2 police officers and one GLAA official. Unfortunately, despite energetic and protracted attempts to engage with the immigration service and numerous police forces, all with first responder roles in identifying instances of modern slavery, all but two police forces refused to participate, without explanation.

Semi-structured interviews were deployed because this enabled participants to move the discussion into unforeseen territory. Forced labour manifests itself in ever changing forms and in this way, interviewees could provide insights into the crime of forced labour through the rich data of their explanations, descriptions, perceptions and understandings. The intention was to accumulate insights into victim experiences and to generate 'in-depth personal accounts', of the 'complex processes and issues' behind the challenges faced by enforcing authorities and first responders tasked with uncovering the crime (Lewis 2003:60). Interview transcripts were input into the Nvivo computer package to facilitate thematic analysis. All transcripts were analysed and re-analysed to identify emergent themes.

The study was undertaken in the knowledge that pre-existing quantitative data had inherent limitations, sufficient only to confirm the presence of forced labour in the UK. National Referral Mechanism (NRM) data concerned only victims who had entered the NRM system. It lacked detail on referring agency, the manner or exact location of exploitation, or how the victim had been discovered. There is no information about individuals who declined the referral (NCA, 2016b). Data from prosecutions were also inadequate. For example, cases were recorded under a composite heading 'Modern Slavery' with no differentiation of forced labour cases or offences prosecuted using non slavery laws (Haughey, 2016:12).

The research was governed by University of Hull ethical requirements and accordingly reviewed by the faculty ethics committee. Approval was subject to consultation on any further issues emerging during research. No ethical dilemmas emerged. All participants gave informed consent and were assured of anonymity and confidentiality. 


\section{Findings}

The study corroborated previous research that forced labour remains a significant presence within a wide range of industries in the UK (Wilkinson et al., 2010; Scott et al., 2012; Craig et al., 2007). Strong links between forced labour and migration, especially the undocumented, were demonstrated and strong associations confirmed between exploitation at work and sub-standard accommodation. The study further found that found victims encountered barriers to accessing support and that many were reluctant to contact the authorities.

The most striking new finding of the study was that many officials, among them first responders, were significantly deficient in their comprehension of the scope of forced labour. Their capacity to identify a potential case and react appropriately was poor. Government officials from a wide range of agencies are simply not comprehending the significance of the circumstances they appear to encounter regularly. Every respondent interviewed had experienced at least one unsettling and potentially exploitative work situation but had taken no further action. Unhelpful working arrangements further constrain official activity. These themes will be now be explored in more detail.

\section{Official Experiences}

An HSE Inspector recalled investigating an accident that paralysed a Polish worker for life. He found fellow workers had attempted to obscure the circumstances by carrying him off-site. No-one on site would agree to cooperate with the subsequent investigation and the matter was closed. Similarly, an EHO explained :

'I walk into businesses that I know will probably sell four or five pizzas a night and somehow manage to sustain a workforce of about five or six people. So you think how on earth is that business surviving?

Another EHO said:

'The manager was Chinese but all the staff were Romanian. She didn't know any of their names. I said “well that's odd." If she's a manager she should at least 
know the first name: Mary, Bob, Fred whatever, and if they're not speaking English how does she communicate with them?'

The study exposed the need for a flexible and open minded approach for spotting cases of forced labour. The way forced labour manifests in the UK constantly evolves. Every element of the crime varies from the type and location of the work, nationality of victims, to the way they are coerced. Respondents reported wily and innovative exploiters, altering their behaviour in response to enforcement initiatives to avoid detection. A GLAA inspector said:

'We insist during our compliance inspections that each worker must have their own bank account. But the gangmasters are one step ahead of us. So they open bank accounts for all these individuals. But now they've looked at it as another source of revenue. So they won't just open one bank account, they'll open many bank accounts without the worker knowing, with their details, then they'll claim benefits for that person'.

Continuing:

'In the early days they would all go into multi occupancy housing which was easily identifiable. ... Now ... they tend to choose 3 bedroom semi -detached properties that look completely ordinary from the front, and very often they will get the workers to use the back entrances only. So that for all intents and purposes ... you're looking at the neighbours'.

It is imperative that officials know how to look beyond the superficial and focus on detecting key elements of the offence of forced labour whatever the surrounding circumstances. It was obvious that few respondents to the study were conversant with 'Indicators'.

For most respondents, the possibility of encountering serious exploitation in a UK work place had simply never occurred to them, suggesting that despite public awareness campaigns and their own particular connection to inspection or enforcement in the world of work, there remained widespread ignorance of modern slavery. Even where officials were alert to the possibility of exploitation, many did not know who to inform. 
In 2017, Craig (2017:21) found there was 'no group of concerned professionals... where the level and quality of training for identifying and supporting victims of modern slavery, and of knowing how to progress their cases, can be regarded as adequate.' The majority of respondents to this study reflected this and had not received any effective or useful training about forced labour. For example, they had not studied real cases, not been given aide memoires listing indicators and not been instructed on procedure if they encountered a case. The picture for policing was mixed. One officer described her own force as proactive and committed to providing training over and above College of Policing packages, complaining the latter were not fit for purpose: I think it was generic and that wasn't enough for somebody to turn round and go that's forced labour'. Another officer pointed to training provision being patchy, ad hoc and not compulsory: 'Each force is different and has different training needs according to what presents itself'. Greater Manchester Police illustrated the potential benefits of training. After training on modern slavery, the number of forced labour cases the force identified increased by 300\% (GRETA 2016:295).

\section{Working in Silos}

Respondents cited preoccupation with their own primary duties, invariably considerable, as one reason for doing nothing about exploitative environments they encountered. One EHO explained: 'Obviously for me if I'm dealing with dirty premises then unfortunately that takes precedence over anything else ... my primary remit.' Similarly, a Fire Brigade Officer:

'When you are dealing with fire safety issues where you are considering prosecuting, prohibition things like that, you're so focused on "Right, I've got to get this right legally. This might wind up in court." ... I need to gather this evidence and ... people are so technically focused in their jobs ... they may not be looking at the bigger picture'.

Respondents were reluctant to share details, perceived as trivial, about potentially exploitative situations with other agencies. Casual and easy communication between different agencies was rare. One local government officer explained the quandary: "Oh I don't think I should. That is someone else's job." Or, "Can't do that. That is the police's job.... I do not know how I am going to be received." Another EHO: 'I've previously been in contact with other investigatory bodies, but I think sometimes their 
bar is quite high. You know the selection criteria for them to take it on any further is quite a challenge'. As a result, potentially crucial information about concerning situations is not passed on to a more appropriate agency.

This is particularly significant. Many forced labour indicators, such as debt bondage, withheld wages, retention of identity documents, excessive overtime, abuse of vulnerability and deception cannot simply be observed. Their existence has to be confirmed through detailed investigation of the business practices and individual work contracts and arrangements. Swift and decisive inter-agency communication about apparently trivial issues allows for prompt action by an appropriate authority. This offers the best chance of confirming something more sinister.

Reluctance to pass information forward, or indeed, any delay in so doing can have a significant impact on outcomes. A GLAA representative explained:

'It is imperative that if you're going to start meddling in any of these organised crime groups that what you do is done properly on the first instance because you're not getting a second bite. ... because very often ... even if they get a whiff that you're sort of looking around ... (there were) places in Cambridge last year where houses of up to 14 or 15 people just disappeared overnight'. A reluctance to share information was exacerbated by the current reduced capacity of government agencies and the lack of managerial direction to seek out forced labour.

\section{A decline in proactive investigations}

It became clear that government policies were themselves acting as barriers to the identification and support of victims of forced labour. The Hampton Review of regulatory inspection and enforcement (Hampton, 2005) and the post-2010 'Red Tape Challenge' (2011) both proposed replacing speculative inspection with intelligence-based 'risk assessment' inspections. This has proved problematic on several levels. Superficially, it sends the message to exploiters that inspection is unlikely. The chance of officials unexpectedly discovering an instance of forced labour are reduced, while mistreated workers are less likely to encounter officials. 
Post-2010 austerity drives imposed significant funding cuts on government enforcement and inspection agencies, reducing the number and calibre of officials. Institutional knowledge was lost and operational effectiveness adversely impacted. An EHO explained:

'We've seen a loss of long in the tooth experienced uber competent senior managers. I think there's a different mould of officer coming through, those that are more attuned to the new ways of working around priorities. ... I think we are seeing a loss of competency'.

Austerity measures have limited the capacity and scope of the work achieved, while constant reorganisation and restructurings have impacted negatively on officer morale. Austerity burdens individual officials. Everyone has to do more to cover the shortfall in personnel and some now spend a significantly larger percentage of their time on reactive work. This restricts the time for planned visits and therefore limits the opportunities for officials to see what is happening within businesses. An HSE official revealed:

'More and more of our time is spent on investigations and not proactive inspections. I think it's running at about $80 / 20$ or $70 / 30$.... It's a massive shift. That is creating all sorts of knock on effects in terms of levels of stress, burn out and stuff like that. We're more focused on accidents and complaints than ever before.'

Likewise, a local authority official explained:

'Austerity measures - There's only me doing a whole district. So it's reduced our effectiveness to target our primary role but it also affects the amount of intelligence that we can feed back to the other agencies.'

An HSE inspector reported that 'There is no longer any proactive inspection of agriculture,' although a colleague believed 'Farmers don't take any notice of what we say anyway, so what's the point'. If these perspectives represent a general trend, given that agriculture is an area strongly associated with forced labour, this is a very worrying development. Similarly, the GLAA also operates on a very limited budget, with a modest number of inspectors. Initial funding cuts post-2010 were reversed by a modest increase, but as Craig (2017:22) pointed out:

'the GLA's remit, covering about 0.5 million workers in the food-related industrial sectors, was being monitored by a workforce at the GLA of 70 staff of which 40 were 
field staff. The new all-encompassing GLAA has, technically a target of upwards of 30 million workers but is only being offered resources for an additional 40 staff.'

Their current inspection regime is governed by the same principles as other agencies, with speculative inspections replaced by an assessment of risk through intelligence gathering. A cynical commentator might assert that the agency was being set up to fail. Currently, there is no inspection regime or agency tasked with seeking out forced labour on a routine basis. The police have the duty to investigate and prosecute the crime, but they do not have natural or regular contact with workplaces and, as with the GLAA, in the main they are reactive to intelligence in the form of victim complaint, public or agency concerns.

\section{Reluctance of Victims to self-present}

The study confirmed that victims were reluctant to seek assistance. Fear of abuser reprisal and/or of deportation was perceived as the principal reason, but this was not always the case. A police respondent explained:

'In many, many cases you speak to the victims and they don't even identify themselves as victims. With nail bars for example.... they'll be there $4 / 5$ years ... and you speak to them and they're like "oh I'm here just doing my training," and they don't see the fact that they are being exploited and it actually is forced labour.'

A trade union leader suggested an explanation:

"“Well I left a worst situation in Poland to come here. ... Of course I'm going to be exploited. Things will get better when I can get my family here ...".

A victim of forced labour wishing to come forward must surmount many obstacles to obtain official assistance. Time and money saving administrative devices, prompted by austerity measures, make officials less accessible to the public and limit direct contact between official bodies and workers. For example, centralised phone dependent complaint teams prevent people talking, face to face, with local officials. Offices relocated away from high streets to cheaper, remote sites, combined with restricted opening hours, reduce opportunities for complainants to make direct contact. The study found official preference for contact by email, with web sites the gateway to the organisation. Inevitably, these measures are barriers, 
especially for those with limited English language skills, inhibiting victims of forced labour from seeking assistance.

Official self-help provisions are generally neither helpful nor accessible. The Pay and Workers Rights Helpline recommends an initial approach to the employer: a useless suggestion for an exploited worker. Notoriously, until recently, a significant fee was required to access an Employment Tribunal. When contact is made with government officials, their responses to public concerns and victim complaints about modern slavery reportedly range from indifference to incredulity, with genuine problems dismissed as fanciful. For some, experience showed there was little to be gained through pressing the issue, having visited the police only to be told it was 'not a police matter' (Wilkinson et al., 2010:40). The Police Inspectorate described potential victims of modern slavery treated primarily as immigration offenders from the outset with 'troubling examples ... of officers who appeared reluctant to identify and uncover cases of modern slavery and human trafficking due to the volume of complex work that such cases may generate, or because of uncertainty about how to proceed' (HMICFRS, 2017:45).

This behaviour of front-line officers is not unique to the UK. Similar attitudes have been identified elsewhere in Europe, for instance, in relation to children trafficked in to the sex trade (Vidra et al., 2018:656-8). For fear of reprisals, a complainant may wish to remain anonymous. But unless a complaint is authenticated with full particulars of the complainant and comprehensive details of the workplace /employer - something many victims and even the public do not have - and unless it comes under the specific remit of the agency in question - there is widespread reluctance among government agencies to accept it. An HSE respondent explained: 'if someone rang up with a complaint about forced labour. I could quite imagine the (team)... going "and what is the health and safety issue here?" ... I could imagine them putting them right off'. Another EHO commented that 'We don't necessarily have people we could get easily to deal with ....migrants who just don't have English as their first language'.

\section{An environment conducive to exploitation}

It has been argued that forced labour is not an isolated criminal activity, but rather one end of a continuum with decent work at the other end (Skrivankova 2010:18). It has further been 
argued that it is 'hidden' in a range of practices intrinsic to a neo-liberal, free market employment environment, for instance, gangmaster and agency employment and the wholesale sub-contracting of labour, and further, that such an environment actually encourages and facilitates modern day slavery (Wilkinson, 2018). The current government has encouraged the growth of the "gig economy" and of agency-based employment. In November 2017, Good Work: The Taylor Review of Modern Working Practices noted the adverse impacts of the 'gig economy' on worker terms and conditions, the blurring of the boundaries between decent work and modern slavery practices, and the creation of an encouraging environment for exploiters. It held that the pervasive presence of less than decent work, camouflaged more serious exploitation such as forced labour (Taylor, 2017:110-111). This study echoed these findings.

Since 2010, successive governments have calculatedly created a 'hostile environment' for undocumented migrants via "Go home or face arrest" billboards, an escalation of immigration raids, accompanied by increasingly draconian penalties for those employing them: initial fines of $£ 5000$ per undocumented worker increased to $£ 20,000$ in 2014 (Bloch, et al., 2014). The Immigration Act 2016 introduced further restrictive measures creating 'illegal worker' status, obliging landlords to check immigration status, and prohibited undocumented workers from holding bank accounts in England. The then Prime Minister made highly visible threats to increase the rate of deportations and to confiscate the wages of the undocumented as the proceeds of crime (Morris, 2015). Welfare machinery is increasingly unwelcoming too.

Official guidance encourages front line staff, across a range of public services, to question the eligibility of migrants to those services (Guentner, et al., 2016). It's not surprising that exploited illegal workers are reluctant to approach potentially supportive agencies.

\section{Conclusions}

The key findings of the study were that although the UK government instituted the structures required under international conventions to tackle forced labour, it provided neither strategic direction nor a joined-up response in its processes and practices to identify victims and perpetrators. As a consequence, many NRM First Responders do not feel confident in their ability to identify and report instances of forced labour and, as a consequence, victims who might otherwise have been assisted continue to be exploited. Despite evidence of its benefits, 
effective training and advice on the importance of sharing information about forced labour indicators has not been extended to all front-line officials.

Enforcement agencies generally continue to work in silos. Links between the police, GLAA and other public-facing agencies require strengthening, with greater clarification of roles and responsibilities in relation to Forced Labour. Unduly bureaucratic protocols at some government agencies deter victims from coming forward. There is no effective publicity directing victims to multi-lingual advice which also allays the fear of deportation through reassurance that 'illegal worker status' will be disregarded for those confirmed as victims of modern slavery. A further key deficit is the lack of trade union involvement, at any level, in official processes of victim identification.

Despite the introduction of the IASC role, tasked with maintaining strategic oversight of anti-slavery strategies, the primary focus to date has been on mechanisms for legal enforcement. There is no indication that broader social, economic, asylum and immigration policies are similarly appraised with respect to their likely impact on exploitative practices.

The research highlighted the inherent contradictions in current government pronouncements on the need to tackle forced labour and support its victims whilst imposing austerity measures and a 'hands-off' investigatory regime that has significantly limited the capacity of enforcement agencies. Over the past two decades, successive governments have remained wedded to a neo-liberal political and economic agenda, maintaining and extending a deregulated employment environment in which labour exploitation thrives. In response to an increasingly nationalistic and chauvinist zeitgeist, they have also actively generated a 'hostile environment' for undocumented migrant workers and asylum seekers that can only render these people yet more vulnerable to the activities of the worst of exploiters. In the post-Brexit political climate, it is difficult to foresee anything other than that such tendencies will be exacerbated unless the government pays more than lip service to anti-slavery measures.

Further, we would advise that the government acknowledge that enforcement measures alone will not stem the tide of exploitation and that government begin the process of rolling back the macroeconomic conditions and the anti-immigration environment that make severe labour exploitation such an attractive and viable proposition. As a first step towards this, a "slavery 
test" or assessment should be introduced so that every government measure and initiative is appraised for its potential impacts.

\section{References}

Anderson B and Rogaly B (2005) Forced Labour and Migration to the UK: Study Prepared by COMPAS in Collaboration with the Trades Union Congress. London: Trades Union Congress

ATMG (2013) In the Dock. Examining the UK's criminal justice response to trafficking. London:ATMG.

ATMG (2016) Class Acts? Examining modern slavery legislation across the UK. London: Anti-slavery International for ATMG.

Beatty C, Foden M et al. (2015) Benefit sanctions and homelessness: A scoping report. London: CRISIS.

Bloch A, Kumarappan L et al. (2014) Employer sanctions: The impact of workplace raids and fines on undocumented migrants and ethnic enclave employers. Critical Social Policy 35(1): $132-151$

Brewer K (2018) Asylum decision-maker: 'It's a lottery'. BBC News . Available at: https://www.bbc.co.uk/news/stories-43555766 [Accessed 8 May 2018]. Broadbent P (2017) Tackling Labour Exploitation. [Presentation] REC Policy and Legal Webinar 21/3/2017.

Corporate Watch (2016) Snitches, Stings \& Leaks: How Immigration Enforcement Works. https://corporatewatch.org/snitches-stings-leaks-how-immigration-enforcement-works-2/ Craig G, Gaus A et al. (2007) Contemporary slavery in the UK. Overview and key issues. York: Joseph Rowntree Foundation.

Craig G (2017) The UK's Modern Slavery Legislation: An Early Assessment of Progress. Social Inclusion 5(2).

Crown Prosecution Service (CPS) (2016) Prosecution policy and guidance: legal guidance: human trafficking, smuggling and slavery. Available online: http://www.cps.gov.uk [Accessed 28/11/2016].

Centre for Social Justice (CSJ) (2013) It happens here: equipping the United Kingdom to fight modern slavery. London:CSJ. 
Field F, Miller M and Butler-Sloss Baroness (2018) Independent Review of the Modern Slavery Act. Second Interim Report: Transparency in supply chains. (CP100)

Fouladvand S (2015) Human trafficking and cannabis cultivation: new horizon of crime and risk in the countryside. Available online:

https://cdn.harper-adams.ac.uk/document/page/239_Human-Trafficking-and-Cultivation-of-C annabis.pdf [Accessed 18/7/2017].

Gentleman A (2017) Trafficked and Enslaved: the teenagers tending UK cannabis farms. The Guardian. Saturday, 25 March, 26.

Global Slavery Index (2019)

https://www.globalslaveryindex.org/2018/findings/country-studies/united-kingdom/

[Accessed 15/4/ 2019].

GRETA (2016) Report concerning the implementation of the Council of Europe convention on Action against trafficking in human beings by the United Kingdom. Available online: https://rm.coe.int/CoERMPublicCommonSearchServices/DisplayDCTMContent?documentId $=09000016806 \mathrm{abcdc}$ [Accessed 3/1/ 2017].

Grierson J (2017) Tens of thousands of modern slavery victims in UK, NCA says. The Guardian 10 Aug 17.

https://www.theguardian.com/world/2017/aug/10/modern-slavery-uk-nca-human-traffickingprostitution. [Accessed: 12/8/2017].

Guentner S, Lukes S et al. (2016) Bordering Practices in the UK Welfare System. Critical Social Policy 36(3): 391-411.

Hampton P (2005) Reducing administrative burdens: effective inspection and enforcement. London: HMSO.

Haughey C (2016) The Modern Slavery Act review. Available online: http://www.gov.uk/government/uploads/system/uploads/attachment_data/file/542047/2016_0

7_31_Haughey_Review_of_Modern_Slavery_Act_-_final_1.0.pdf. [Accessed: 22/8/2016]. HM Government (2014) Modern Slavery Strategy. HMSO

HMICFRS (2017) Stolen freedom: the policing response to modern slavery and human trafficking.

Home Affairs Committee, Home Office delivery of Brexit: immigration, Oral Evidence, David Wood HC 421,Tuesday 10 October 2017, Q36 response. 
Home Office (2014) Final report on the Home Office Powers of Entry Review. London: Williams Lea Group for HMSO.

IASC (2015) Strategic Plan 2015-17.

https://www.antislaverycommissioner.co.uk/media/1075/iasc_strategicplan_2015.pdf ICIBI (2017) An Inspection of Border Force's Identification and Treatment of Potential Victims of Modern Slavery, July to October 2016. Independent Chief Inspector of Borders \& Immigration.

Independent anti-slavery commissioner (2016) Annual report for the period 1 August 2015 to 30 September 2016. UK:Williams Lea Group for HMSO.

Independent Asylum Commission (2008) Safe return: The Independent Asylum Commission's Second Report of Conclusions and Recommendations. Available at: http://www.independentasylumcommission.org.uk/files/Safe\%20Return\%20final.pdf (accessed May 2019).

Institute for Public Policy Research (IPPR) (2006) Irregular Migration in the UK: IPPR factfile, Migration and Equalities Team, London, IPPR (2006)

ILO (2012) ILO Indicators of Forced Labour.

https://www.ilo.org/wcmsp5/groups/public/---ed_norm/---declaration/documents/publication/ Wcms_203832.pdf

ILO (2014) Protocol of 2014 to the Forced Labour Convention, 1930, and the Forced Labour (Supplementary Measures) Recommendation (No. 203), 2014 https://www.ilo.org/wcmsp5/groups/public/@ed_norm/@declaration/documents/publication/ Wcms_508317.pdf

Kidd A, Faulkner E et al (2019) How UK asylum system creates perfect conditions for modern slavery and exploitation to thrive. In:The Conversation. 8 Apr 2019.Available at: https://theconversation.com/how-uk-asylum-system-creates-perfect-conditions-for-modern-sl avery-and-exploitation-to-thrive-113778

Lewis H, Dwyer P et al. (2015) Precarious Lives Forced Labour, Exploitation and Asylum. Bristol: Policy Press.

Lewis J (2003) Design Issues. In Ritchie, J. \& Lewis, J. (eds) Qualitative Research Practice. A guide for Social Science Students and Researchers. London: Sage Publications, 47-76. . Lyons K, Kirchgaessner S et al. (2017) Britain is one of worst places in western Europe for asylum seekers. The Guardian. 1 Mar 17[Accessed 1/4/2017]. 
Macpherson of Cluny W (1999) The Stephen Lawrence Inquiry (Cm 4262-1). London:TSO. Morris N (2015, 21 May) Illegal immigrants' pay will be seized, pledges David Cameron The Independent NCA (2016a) Moderns Slavery Human Trafficking Unit (MSHTU). Available at: https:// www.nwgnetwork.org/services/modern-slavery-human-trafficking-unit-mshtu/ NCA (2016b) Human Trafficking: National Referral Mechanism Statistics Q1 January to March 2016. (Reference: 0299-UKHTC Version number: 1.0.) Available online: www.nationalcrimeagency.gov.uk [Accessed September 2016]. NCA (2018) County Lines Drug Supply, Vulnerability and Harm 2018. NAC (19) 095 https://nationalcrimeagency.gov.uk/who-we-are/publications/257-county-lines-drug-supply-v ulnerability-and-harm-2018/file PROTECT (2015) Provider Responses Treatment and Care for Trafficked People. Available at: http://clok.uclan.ac.uk/14394/1/PROTECT\%20Final\%20Report.pdf Scott S, Craig G et al (2012) Experiences of forced labour in the UK food industry. York: Joseph Rowntree Foundation.

Shepherd R (2018) The scale and extent of Forced Labour in the UK: Can the existing legislative and administrative arrangements address the problem? $\mathrm{PhD}$ Thesis, University of Hull, UK.

Silverman B (2014) Modern Slavery: an application of multiple systems estimation. Home Office.https://assets.publishing.service.gov.uk/government/uploads/system/uploads/attachme nt_data/file/386841/Modern_Slavery_an_application_of_MSE_revised.pdf Skrivankova K (2006) Trafficking for forced labour: UK country report. London: Anti-Slavery International.

Skrivankova K (2010) Between decent work and forced labour: examining the continuum of exploitation. York: Joseph Rowntree Foundation.

Souter J (2011) A Culture of Disbelief or Denial? Critiquing Refugee Status Determination in the United Kingdom. Oxford Monitor of Forced Migration. February 1(1) 48-59.

Standing G (2011) The Precariat: The New Dangerous Class. Bloomsbury Academic. Taylor D and Muir H (2010) Border staff humiliate and trick asylum seekers - whistleblower. The Guardian 2 Feb, 2010 Available at: http://www.theguardian.com/uk/2010/feb/02/border-staff-asylum-seekers-whistleblower Taylor M (2017) Good work: The Taylor Review of Modern Working Practices. London: 
Department for Business, Energy \& Industrial Strategy. The Commission on Vulnerable Employment (CoVE) Hard Work, Hidden Lives', Full Report. CoVE May 2008 The Red Tape Challenge. Available at: https://www.gov.uk/government/news/red-tape-challenge

Travis A (2017) UK Border Force 'failing to identify thousands of modern slavery victims.' The Guardian. 2 Feb 2017.

UK Government (2015) The Modern Slavery Act, 2015. The Stationery Office.

Vernalls R (2017) Eleven members of same family convicted over modern slavery ring. The Independent. 11 Aug

Vidra Z, Katona N et al. (2018) State policies and institutional procedures and practices addressing prostitution and sex trafficking of children in Hungary. Critical Social Policy 38 (4): 645-666.

Wilkinson M, Craig G et al (2010) Forced Labour in the UK and the Gangmasters Licencing ity. Hull: The Wilberforce Institute, University of Hull.

Wilkinson M (2018) Modern Slavery: The Neoliberal UK Model. The Socialist Correspondent 31, Summer 2018. 